Article

\title{
Enhancement in Oral Absorption of Ceftriaxone by Highly Functionalized Magnetic Iron Oxide Nanoparticles
}

\author{
Muhammad Kawish ${ }^{1}$, Abdelbary Elhissi ${ }^{2}$, Tooba Jabri ${ }^{1}$, Kanwal Muhammad Iqbal ${ }^{1}$ (D), \\ Hina Zahid ${ }^{3}$ and Muhammad Raza Shah ${ }^{1, *}$ \\ 1 International Center for Chemical and Biological Sciences, H.E.J. Research Institute of Chemistry, \\ University of Karachi, Karachi 75270, Pakistan; kawishiqbal02@iccs.edu or kawishiqbal02@gmail.com (M.K.); \\ toobaasif137@iccs.edu or toobaasif137@gmail.com (T.J.); \\ kanwal.iqbal@iccs.edu or kanwalmuhammadiqbal43@gmail.com (K.M.I.) \\ 2 College of Pharmacy, QU Health, and Office of VP for Research and Graduate Studies, Qatar University, \\ Doha 2713, Qatar; aelhissi@qu.edu.qa \\ 3 Faculty of Pharmaceutical Sciences Dow University of Health Sciences Karachi, Karachi 74200, Pakistan; \\ hina.zahid@duhs.edu.pk or hinazahid.zh@gmail.com \\ * Correspondence: raza.shah@iccs.edu; Tel.: +92-111-222-292 (ext. 233)
}

Received: 13 March 2020; Accepted: 20 May 2020; Published: 28 May 2020

\begin{abstract}
The present study aims at the development, characterization, biocompatibility investigation and oral bioavailability evaluation of ceftriaxone (CFT)-loaded $\mathrm{N}^{\prime}$-methacryloylisonicotinohydrazide (MIH)-functionalized magnetic nanoparticles (CFT-MIH-MNPs). Atomic force microscopy (AFM) and dynamic light scattering (DLS) showed that the developed CFT loaded MIH-MNPs are spherical, with a measured hydrodynamic size of $184.0 \pm 2.7 \mathrm{~nm}$ and negative zeta potential values $(-20.2 \pm 0.4 \mathrm{mV})$. Fourier transformed infrared spectroscopic (FTIR) analysis revealed interactions between the nanocarrier and the drug. Nanoparticles showed high drug entrapment efficiency (EE) of $79.4 \% \pm 1.5 \%$, and the drug was released gradually in vitro and showed prolonged in vitro stability using simulated gastrointestinal tract (GIT) fluids. The formulations were found to be highly biocompatible (up to $100 \mu \mathrm{g} / \mathrm{mL}$ ) and hemocompatible (up to $1.0 \mathrm{mg} / \mathrm{mL}$ ). Using an albino rabbit model, the formulation showed a significant enhancement in drug plasma concentration up to $14.4 \pm 1.8 \mu \mathrm{g} / \mathrm{mL}$ in comparison with its control $(2.0 \pm 0.6 \mu \mathrm{g} / \mathrm{mL})$. Overall, the developed CFT-MIH-MNPs formulation was promising for provision of high drug entrapment, gradual drug release and suitability for enhancing the oral delivery of CFT.
\end{abstract}

Keywords: iron oxide nanoparticles; surface functionalization; biocompatibility; ceftriaxone; oral delivery

\section{Introduction}

Oral drug administration is the most established strategy for achieving improved clinical outcomes of drugs. The oral route is devoid of discomforts associated with the intravenous route, thus providing higher patient compliance and no need for hospital admission to administer the dose. The oral route can also be used for delivery of less water-soluble drug molecules that cannot be administered through other routes [1]. However, drugs delivered through the oral route have to face various obstacles such as instability and insolubility in the harsh acidic gastric environment, degradative effects of digestive enzymes and poor absorption through the intestinal epithelium which results in poor drug bioavailability [2,3]. Recent developments in the field of nano-drug delivery systems have demonstrated improved oral delivery of various drug formulations through protection from enzymatic 
degradation and improved absorption through the intestinal epithelium. They also improve the oral delivery of drugs through organ-specific localization with a controlled release manner [4].

Magnetic nanoparticles (MNPs) are widely considered a promising drug delivery system due to their distinct advantages such as well-documented bio-safety, ease of preparation and handling, the possibility for controlling their characteristics, affordability of materials needed and the possibility of targeting the drugs to a desired location. Furthermore, core-shell MNPs have attracted much attention due to their multifunctional properties such as small size, superparamagnetism and low toxicity $[5,6]$. Silica-coated MNPs are one of the most extensively used NPs which possess very high specific surface with abundant $\mathrm{Si}-\mathrm{OH}$ or $\mathrm{Si}-\mathrm{NH}_{2}$ groups with the ability to react with proper functional groups $[7,8]$. Besides these advantages, various issues such as their rapid aggregation and early clearance from blood circulation by the reticuloendothelial system (RES), reduce their therapeutic efficacy [8,9]. Encapsulation of MNPs within biodegradable and biocompatible substances is one approach for addressing these issues [10].

Additionally, encapsulation of MNPs with other molecules can be used by inserting desirable and diverse functionality for the conjugation of drugs [11]. Surface functionalization of MNPs for specific purposes such as enhancement in the oral bioavailability of drugs has attracted increased attention. MNPs bearing a surface enriched with hydroxyl groups can constitute a potential mucoadhesive carrier for enhancing oral bioavailability of their loaded drugs [12].

Ceftriaxone (CFT), a third-generation cephalosporin, is capable of inhibiting the biosynthesis of the bacterial cell wall. CFT is widely prescribed for the treatment of various infections such as urinary tract infections, endocarditis, meningitis and pneumonia. However, oral delivery of CFT is a real challenge, constituting one of the limitations of this drug. It belongs to class III drugs in the biopharmaceutical classification system and suffers from lower membrane permeability. This leads to poor biological performance of the drug after its oral administration [13,14]. CFT is poorly absorbed through the mucosal membrane of the intestine due to its two negatively ionized carboxyl groups [15]. Thus, a versatile nanocarrier surface functionalized with molecules having multi-hydroxyl groups is highly desirable for oral delivery of CFT.

For the first time, the present investigation was based on the delivery of CFT through drug conjugated nanoparticles (NPs) for the enhancement of oral bioavailability of the drug. For this purpose, isoniazid was functionalized on MNPs to get a supramolecular core-shell nanostructure. We investigated whether the developed NPs were capable of stacking and stabilizing CFT electrostatically with the aid of pyridine moiety in isoniazid against harsh stomach conditions. We further evaluated the ability of NPs to offer therapeutic loadings of CFT and the mechanism of interaction between CFT and the NPs. The synthesized nanoparticles were also characterized in terms of their drug loading capacity, size, surface charge and drug release profile. In addition, biocompatibility and stability studies were conducted and using a rabbit animal model, the in vivo oral bioavailability investigations were performed.

\section{Methods and Materials}

\subsection{Materials}

All solvents utilized in experiments were of HPLC grade and obtained from Fisher Scientific, (Loughborough, UK) Ferric sulphatehexahydrate $\mathrm{Fe}_{2}\left(\mathrm{SO}_{4}\right)_{3} \cdot 6 \mathrm{H}_{2} \mathrm{O}$, ferrous sulphate heptahydrate $\left(\mathrm{FeSO}_{4} \cdot 7 \mathrm{H}_{2} \mathrm{O}\right)$, 3-(trimethoxysilyl)propyl methacrylate (MPTES), 4-dimethyl aminopyridine (DMAP), azobisisobutyronitrile (AIBN), ammonium hydroxide, dicyclohexylcarbodiimide (DCC) and methacrylic acid (MMA) were obtained from Sigma-Aldrich (St. Louis, MO, USA), Merck (Darmstadt, Germany and ceftriaxone (intravenous-Infusion) and isoniazid through Getz Pharmaceuticals (Karachi, Pakistan). Fresh human plasma was obtained from Ziauddin University Hospital (Karachi, Pakistan). 


\subsection{Synthesis of $M I H$}

MMA (1.88 g, 21.8 mmol), DMAP (0.26 g, 2.1mmol) and DCC (4.51 g, $21.8 \mathrm{mmol})$ were dissolved in tetrahydrofuran (THF) $(40 \mathrm{~mL})$ in a round bottom flask connected with a condenser. The reaction was stirred for $10 \mathrm{~min}$ at $60^{\circ} \mathrm{C}$ under Ar atmosphere. Isoniazid $(1.0 \mathrm{~g}, 7.29 \mathrm{mmol})$ was added later, and the reaction was refluxed for $24 \mathrm{~h}$ followed by monitoring via thin-layer chromatography using $\mathrm{DCM}$ and $\mathrm{MeOH}(9: 1 v / v)$ as a solvent system. The resulting mixture was concentrated in vacuo and the concentrate was then subjected to column chromatography using flash silica as a stationary phase. Desired pure compound was obtained using hexane and ethyl acetate $(6: 4 v / v)$ as a mobile phase.

Rf, 0.56 (DCM : MeOH, 9:1, v/v),yield 50\%; M.P., 99.3-100.4 ${ }^{\circ}$ C, EI-MS 205.1, ${ }^{1} \mathrm{H}$ NMR (300 MHz MeOD); $\delta$ ppm, 8.70 (d 2Hpyridine), 7.85 (d 2H pyridine), 5.86 (s $1 \mathrm{H}$ amide), 5.51 (s $1 \mathrm{H}$ amide), 3.02 (s $3 \mathrm{H} \mathrm{CH}_{3}$ ).

\subsection{Preparation of $M I H-M N P s$ and CFT-MIH-MNPS}

First, narrow range MNPs were prepared by precipitating $\mathrm{Fe}(\mathrm{III})$ and $\mathrm{Fe}(\mathrm{II})$ in an alkaline medium by a co-precipitation technique [16]. Then, synthesized MNPs underwent surface coating with MPTES through silanization reaction [17] in such a manner that the ratio between MNPs and MPTES remained $1 / 6$ upon incubation for $4 \mathrm{~h}$ at $60^{\circ} \mathrm{C}$. MIH coated MNPs was obtained through radical polymerization method. Briefly, a solution of MPTES-modified MNPs $(0.15 \mathrm{~g})$ and MIH $(0.950 \mathrm{~g}, 4.63 \mathrm{mmol})$ in a ratio of $1: 6$ werestirred for $1 \mathrm{~h}$ at $60^{\circ} \mathrm{C}$ to facilitate the pre-polymerization process. After stirring for $10 \mathrm{~min}, \mathrm{AIBN}(1.3 \mathrm{~g}, 7.91 \mathrm{mmol})$ was added to the resulting mixture and was refluxed for $24 \mathrm{~h}$ under $\mathrm{Ar}$ atmosphere at $60^{\circ} \mathrm{C}$. The obtained MIH-MNPs were washed sequentially with acetonitrile $(\mathrm{ACN})$ and dried at $-20{ }^{\circ} \mathrm{C}$ on a freeze dryer (Vritis 25 S.R.C., New York, NY, USA.) overnight. CFT loading was performed with slight modification of a previously published protocol [18]. Briefly, nanosuspension of MIH-MNPs $(1 \mathrm{mg} / \mathrm{mL})$ was introduced in various concentrations of CFT $(1-5 \mathrm{mg} / \mathrm{mL})$ insuch a way that the ratio between the nanoparticles (NPs) and CFT remained 1:1 (w/w). This was then incubated on a rotary shaker at $200 \mathrm{rpm}$ for $24 \mathrm{~h}$ to facilitate drug uptake. The resultant CFT-MIH-MNPs were removed via centrifugation at $15,483 \mathrm{G}$, and the supernatant containing the unloaded drug was quantified on a UV-Vis spectrophotometer (Shimadzu 1800 series) Shimartzu, Kyoto, Japan. The blend containing a higher amount of drug entrapment was considered for further analysis.

\subsection{Particle Size, Size Distribution, Zeta Potential and Morphology Studies}

The average hydrodynamic diameter and PDI of vacant and CFT loaded MIH-MNPs was investigated via the Zetasizer (Zetasizer Nano ZS90 Malvern Instruments, Malvern, UK). Concisely, diluted NPs were transferred to a transparent plastic cuvette with caution to avoid bubble formation. The cuvette was then placed in the cell holder of the instrument and analysis was taken at 90 degree scattering at $25^{\circ} \mathrm{C}$. The medium viscosity and refractive index options in the instrument's software were kept constant at 1.33 and $80.4 \mathrm{mPa}$, respectively. NPs were also characterized for morphology using AFM (AFM, Agilent 5500) Agilent, CA, USA. A drop of the formulation was placed on a mica slide and air dried at ambient temperature and placed on a microscope. The morphology was investigated at non-contact mode.

\subsection{FTIR Spectroscopy}

FT-IR spectra were obtained by Shimadzu IR-470 spectrometer (Shimadzu, Kyoto, Japan) having a resolution of $4 \mathrm{~cm}^{-1}$, to elucidate the self-assembled layer formed on the surface of NPs. A small number of powdered NPs was mixed with $\mathrm{KBr}$ and subjected to a pressure value of 200 Psi to obtain self-supporting disks. 


\subsection{Stability of NPs in Simulated Gastric Fluids (SGF)}

The persistence of the MIH-MNPs mentioned above, and CFT-MIH-MNPs in SGF was evaluated with a slight amendment of previously published studies [19]. Briefly, the stock SGF was prepared without pepsin by mixing $300 \mathrm{mM} \mathrm{NaCl}$ with a solution containing $840 \mathrm{mM} \mathrm{HCl}$ (pH 1.2). Pancreatin excluding intestinal fluid was prepared and composed of $800 \mathrm{mM} \mathrm{NaHCO}_{3}(\mathrm{pH} 7.4)$. At the predetermined interval, the sample was taken for determination of size and PDI by DLS at $37^{\circ} \mathrm{C}$ using the Zetasizer Instrument (Malvern Instruments Ltd., Malvern, UK). UV-V is spectroscopy analysis was also performed to evaluate the stability of CFT in the SGF medium.

\subsection{Development of HPLC Protocol for the Determination of CFT in Blood Plasma}

The availability of CFT and internal standard cephalexin (CEP) in plasma was determined through reverse phase HPLC protocol developed and validated in our laboratories. The protein precipitation method was taken into account for extracting drug from plasma. Plasma $(200 \mu \mathrm{L})$ containing both drugs was blended and vortexed with $\mathrm{ACN}(400 \mu \mathrm{L})$ for $2 \mathrm{~min}$ and the precipitate was separated by centrifugation at 15,483 $\mathrm{G}$ for $10 \mathrm{~min}$. The acquired supernatant was concentrated in vacuum and reconstituted in buffer (TBAH, $100 \mu \mathrm{L} ; \mathrm{pH} 7.0)$. A volume of $25 \mu \mathrm{L}$ was injected into the HPLC system Shimadzu, LC20A (Shimadzu, Kyoto, Japan) equipped with a purospher C18 (5 $\mathrm{m}, 250 \times 4.6 \mathrm{~mm})$ column. The mobile phase was comprised of ACN and TBAH buffer $(0.005 \mathrm{M}, \mathrm{pH} 7.0)$ in a ratio of 25:75. The flow rate was adjusted to $1 \mathrm{~mL} / \mathrm{min}$, and the wavelength selected was $220 \mathrm{~nm}$.

\subsection{Entrapment Efficiency Determination}

The targeted MIH-MNPs were exploited for drug entrapment efficiency, according to previously reported protocol [20]. The obtained supernatant after centrifugation of CFT-MIH-MNPs suspension was subjected to successive dilution and analyzed at $241 \mathrm{~nm}$ on a UV-Vis spectrophotometer. The drug entrapment efficiency (EE) was calculated by using the following equation:

$$
\mathrm{EE}(\%)=\left[\left(\mathrm{A}_{\text {initial }}-\mathrm{A}_{\text {free }}\right) / \mathrm{A}_{\text {initial }}\right] \times 100,
$$

where $\mathrm{A}_{\text {initial }}$ is theamount of CFT taken for loading and $\mathrm{A}_{\text {free }}$ is theamount of unloaded CFT.

\subsection{In Vitro Release Study}

The drug release experiment was performed in triplicate using three different batches, and the samples were drawn at certain time intervals from the release medium with the replacement of fresh buffer of respective $\mathrm{pH}$. The amount of drug released was determined by spectrophotometry at $241 \mathrm{~nm}$, while maintaining the temperature at $37^{\circ} \mathrm{C}$. Samples ( $5 \mathrm{mg}$ equivalent CFT loaded MNPs were dispersed in buffer, $4 \mathrm{~mL}$; $\mathrm{pH} 4.0$ or $\mathrm{pH} 7.0)$ and immersed in a $50 \mathrm{~mL}$ release medium (pH 4.0 or 7.0). The release rate studies were performed using the dialysis membrane of $12,000 \mathrm{kDa}$ using the dialysis method described in a previous study [21].

\subsection{Hemocompatibility Study}

Ethylenediaminetetraacetic acid (EDTA) stabilized human blood samples (5 mL) were added to $10 \mathrm{~mL}$ of PBS. Red blood cells (RBCs) were then isolated from serum by centrifugation at $3871 \mathrm{G}$ for $10 \mathrm{~min}$. The RBCs were further washed five times with $10 \mathrm{~mL}$ of PBS solution. Purified RBCs were diluted to $50 \mathrm{~mL}$ of PBS. Prior to nanoparticle exposure, the absorbance spectrum was analyzed. Herein, RBCs incubation with Triton $X$ was used as the positive test. Then, $0.2 \mathrm{~mL}$ of diluted RBC suspension was added to $0.8 \mathrm{~mL}$ of MIH-MNPs solution in 200-1000 $\mu \mathrm{g} / \mathrm{mL}$ concentrations, followed by vortex mixing. All sample tubes were kept in static condition at room temperature for $3 \mathrm{~h}$. Finally, the mixtures were centrifuged at $15,483 \mathrm{G}$ for $10 \mathrm{~min}$, and $1.5 \mathrm{~mL}$ of supernatant of each sample was transferred to a cuvette. The absorbance values of the supernatants at $540 \mathrm{~nm}$ were determined 
by UV-VIS spectrophotometer. The percent hemolytic activity of RBCs was calculated using the following equation:

$$
\% \text { H.A. }=\text { Rs } / \text { Rc } \times 100 .
$$

Rs: absorbance of sample; Rc: absorbance of positive control; \% H.A.: hemolytic activity in percent.

\subsection{In Vitro Cytotoxicity Study}

The synthesized nanocarrier was investigated for its cytotoxicity using MTT assay. Both 3T3/NIH and HeLa cells were refined in Dulbecco's Modified Eagle Medium (DMEM) having fetal bovine serum $(10 \%)$ and antibiotics (streptomycin and penicillin, about $50 \mathrm{U} / \mathrm{mL}$ ) at room temperature and under carbon dioxide $(5 \%)$ humid atmosphere. Both cell lines were individually incubated into 96-well plates with $8 \times 10^{3}$ and $6 \times 10^{4}$ cells/well thickness in $200 \mu \mathrm{L}$ refined media. After incubation for $24 \mathrm{~h}$, fresh media $(200 \mu \mathrm{L})$ consisting of NPs was introduced at various concentrations for $100 \mu \mathrm{g} / \mathrm{mL}$. Incubated cells in media without NPs were used as a negative control and developed for 48 h. 3-(4,5-Dimethylthiazol-2-Yl)-2,5-Diphenyltetrazolium bromide solution (MTT) in PBS was introduced in each well $(20 \mu \mathrm{L} ; 5 \mathrm{mg} / \mathrm{mL})$. The unreacted portion was expelled after $4 \mathrm{~h}$ of incubation. The resulting formazan crystals were dissolved and introduced at $200 \mu \mathrm{L}$ DMSO per well and analyzed at $570 \mathrm{~nm}$ in a microplate reader. For positive control and reference standard, doxorubicin (DOX) and cyclohaxanamide (CHX) were used. The following equation was utilized to determine $\%$ cell viability:

$$
\text { Cell viability } \%=\mathrm{At} / \mathrm{Ac} \times 100 \text {. }
$$

At: mean of absorbance value of test sample; Ac: mean of absorbance value of a control.

\subsection{In Vivo Oral Pharmacokinetics Studies}

Animal studies were conducted under institutional guidelines by following the principals of institutional animal care. The studies were approved by the Ethics Committee of International Center for Chemical and Biological Sciences, University of Karachi (Project identification code ICCBS/CBSCR/IEC-014/2018; approved date 06-04-2018). All animals were healthy and purchased for Dow University of Health Sciences OJHA campus Karachi, Pakistan. Rabbits (Oryctolaguscuniculus) with $1.2 \mathrm{~kg}$ normal body weight were chosen for the assessment of oral in vivo pharmacokinetics studies. Rabbits were held under standard quarantine conditions with free access to food and water for $12 \mathrm{~h}$. Before conducting the in vivo studies, rabbits were kept under fasting conditions but with free access to water. Rabbits were divided into three distinct categories $(n=4)$. The first category was given CFT-MIH-MNPs suspension at $25 \mathrm{mg} / \mathrm{kg}$ body weight portion. Rabbits of the second and third categories were provided with CFT in oral aqueous solution at 25 and $50 \mathrm{mg} / \mathrm{kg}$ body weight. Blood samples $(1 \mathrm{~mL})$ were collected via marginal ear vein using an insulin plastic syringe at various intervals within $24 \mathrm{~h}$. After centrifugation at $2688 \mathrm{G}$ for $10 \mathrm{~min}$, plasma was acquired and stored at $-20^{\circ} \mathrm{C}$. Pharmacokinetics parameters were assessed by linear trapezoidal standard using a non-compartmental model from individual drug plasma concentrations with reference to a time curve for CFT after oral administration of nanoformulation and controls separately. The estimations of maximum drug plasma concentration $\left(C_{\max }\right)$ and time to reach maximum plasma concentration $\left(\mathrm{T}_{\max }\right)$ were obtained from the drug plasma concentration curves. These parameters were utilized to ascertain the pharmacokinetics parameters area under the curve from zero to last quantifiable value $\left(\mathrm{AUC}_{0-24}\right)$, mean residence time (MRT) and clearance $(\mathrm{Cl})$.

\subsection{Statistical Analysis}

The investigations were performed with sample size of $n=3$, and outcomes were depicted as mean \pm SEM. Two-way ANOVA pursued by Beffroni test was applied for the examination of different variables, and Student's $t$-tests were utilized for correlation of two categories. $P$ values less than or equal to 0.05 indicated significant differences between the compared groups. 


\section{Results and Discussion}

\subsection{Synthesis of $\mathrm{MIH}$}

In order to develop MIH, MMA was linked with isoniazid through carbodiimide-triggered coupling reaction (Figure 1) which is well known for its reproducibility, selectivity and high yield as previously reported [22,23]. DMAP was added in catalytic amount owing to its multifunctional characteristics as a base and in intermediate formulations by knocking out urea. The whole process was performed under Ar atmosphere to avoid atmospheric interference [24].

The synthesized MIH shows EI-MS spectrum has $\mathrm{M}^{+}$at $m / z 205$ which coincides with the theoretical weight of the compound having a formula containing odd nitrogen $\mathrm{C}_{10} \mathrm{H}_{11} \mathrm{~N}_{3} \mathrm{O}_{2}$. The ${ }^{1} \mathrm{H}$ NMR spectra of synthesized MIH compound shows a series of aromatic doublet around $\delta 7.8 \mathrm{ppm}$ and $8.7 \mathrm{ppm}$ of $2 \mathrm{H}$. Two olefinic protons have also appeared as singlets around $\delta 5.5 \mathrm{ppm}$ and $5.8 \mathrm{ppm}$ of $1 \mathrm{H}$. A singlet observed around $\delta 3.02 \mathrm{ppm}$ corresponds to the methyl group. The reaction yielded $50 \%$ as a product.

\subsection{Preparation of $M I H-M N P s$ and CFT-MIH-MNPS}

Among different routes for the synthesis of MNPs, the co-precipitation method is most preferred for the preparation of MNPs [25]. This method is economical, convenient and provides good control over size distribution and morphology under ambient conditions [26]. Uncoated NPs tend to aggregate and oxidize; therefore, it is necessary to functionalize their surface to prevent aggregation [25]. MPTES was added to stabilize and functionalize pi-bonds onto the surface of MNPs to initiate polymerization [27]. Finally reflux-polymerization was performed using $\mathrm{MIH}$ as a monomer and AIBN as an initiator.

The synthetic scheme of silane-coated MNPs and its MIH conjugated nanostructures is reported earlier [28] and depicted in Figure 1. FT-IR spectra of iron oxide nanoparticles (IONPs) and its surfacefunctionalized analogues is shown in Figure 2. The synthesized IONPs show characteristic absorption around $638.4 \mathrm{~cm}^{-1}$ which is attributed to vibration of Fe-O bonds. Furthermore, absorptions at $1641 \mathrm{~cm}^{-1}$ and $3442.83 \mathrm{~cm}^{-1}$ correspond to stretching and bending vibrations of the hydroxyl groups on the surface of NPs. The functionalization of (MPTES) induces characteristic absorption around $1656 \mathrm{~cm}^{-1}$ and $1775.42 \mathrm{~cm}^{-1}$ of $\alpha, \beta$ unsaturated bond and ester $(\mathrm{C}=\mathrm{O})$, respectively [29]. A frequency of $1056.96 \mathrm{~cm}^{-1}$ observed in the finger print region corresponds to $\mathrm{C}-\mathrm{O}$ bending. Fabrication of $\mathrm{MIH}$ on silane-coated NPs gives a pair of frequencies at $1745.62 \mathrm{~cm}^{-1}$ and $1690 \mathrm{~cm}^{-1}$, and corresponds to the $(\mathrm{C}=\mathrm{O})$ of ester and amide, respectively. A stretch around $1445.6-1560.26 \mathrm{~cm}^{-1}$ corresponds to aromatic ring stretching. The bending vibration around $3463.08 \mathrm{~cm}^{-1}$ and $1641 \mathrm{~cm}^{-1}$ corresponds to $\mathrm{N}-\mathrm{H}$. The characteristic absorption gives evidence for successful functionalization of MIH molecules on the surface of NPs.

To investigate the drug entrapment, FT-IR analysis was conducted of the CFT and CFT-MIH-MNPs loaded formulation [30]. The CFT molecule shows a characteristic absorption at $1748 \mathrm{~cm}^{-1}$ and $1554 \mathrm{~cm}^{-1}$ corresponding to $\beta$ lactam $\mathrm{C}=\mathrm{O}$ and $\mathrm{C}=\mathrm{N}$, respectively [31]. The band shifted to $41 \mathrm{~cm}^{-1}$ of $\mathrm{C}=\mathrm{O}$ and $7 \mathrm{~cm}^{-1}$ of $\mathrm{C}=\mathrm{N}$, lower wavenumbers indicating that $\beta$ lactam moiety was involved in coordination with MNPs. Moreover, the asymmetric stretch of $\mathrm{OH}$ and $\mathrm{NH}_{2}$ would appear at $3455.3 \mathrm{~cm}^{-1}$ and $3288.4 \mathrm{~cm}^{-1}$ (Figure 3), respectively. The band of $\mathrm{OH}$ was shifted to $3485 \mathrm{~cm}^{-1}$ and the peak of $\mathrm{NH}_{2}$ was eliminated, showing that both groups are involved in coordination with nanostructures (Figure 3). The stretching frequency of $\mathrm{COO}^{-}$appeared at $1600 \mathrm{~cm}^{-1}$ as illustrated in Figure 3. The peak was shifted to $1567 \mathrm{~cm}^{-1}$ when it was loaded onto nanostructures, indicating conjugation through that group [32]. It is evident from FTIR comparison that CFT was adsorbed through chelation on MIH-MNPs via amine, carboxylic, beta-lactam and hydroxyl groups. 
<smiles>NC(=O)c1ccncc1</smiles>

Isoniazid<smiles>C=C(C)C(=O)O</smiles>

Methacrylic Acid $\underset{\text { THF, } 24 \mathrm{~h}}{\stackrel{\text { DCC, DMAP }}{\longrightarrow}}$ $60{ }^{\circ} \mathrm{C}$<smiles>C=C(C)C(=O)NNC(=O)c1ccncc1</smiles>

MIH

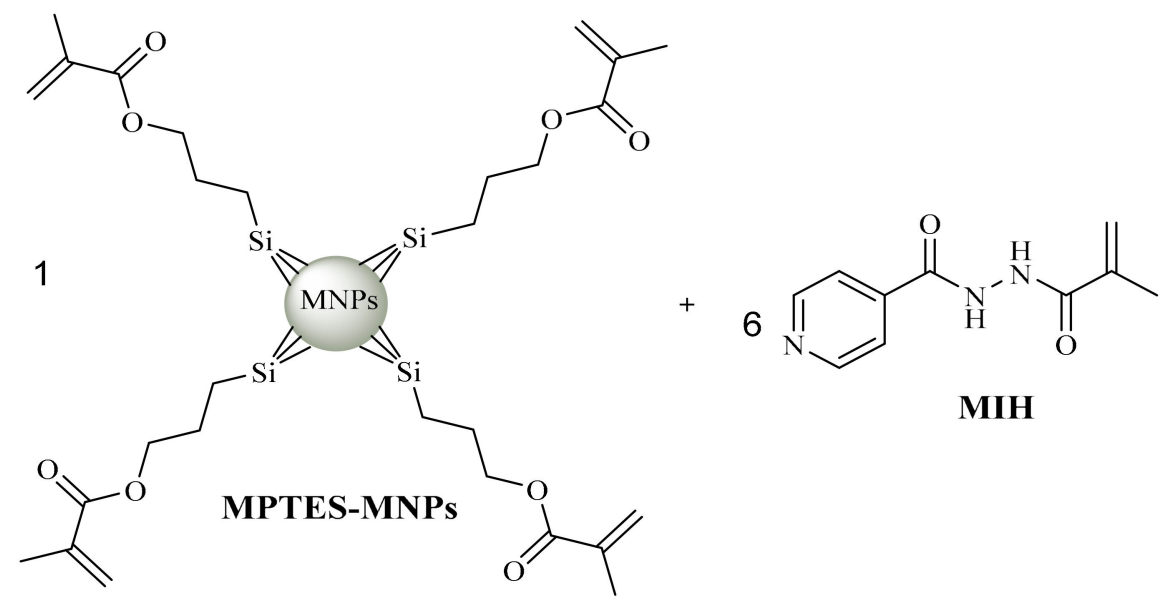

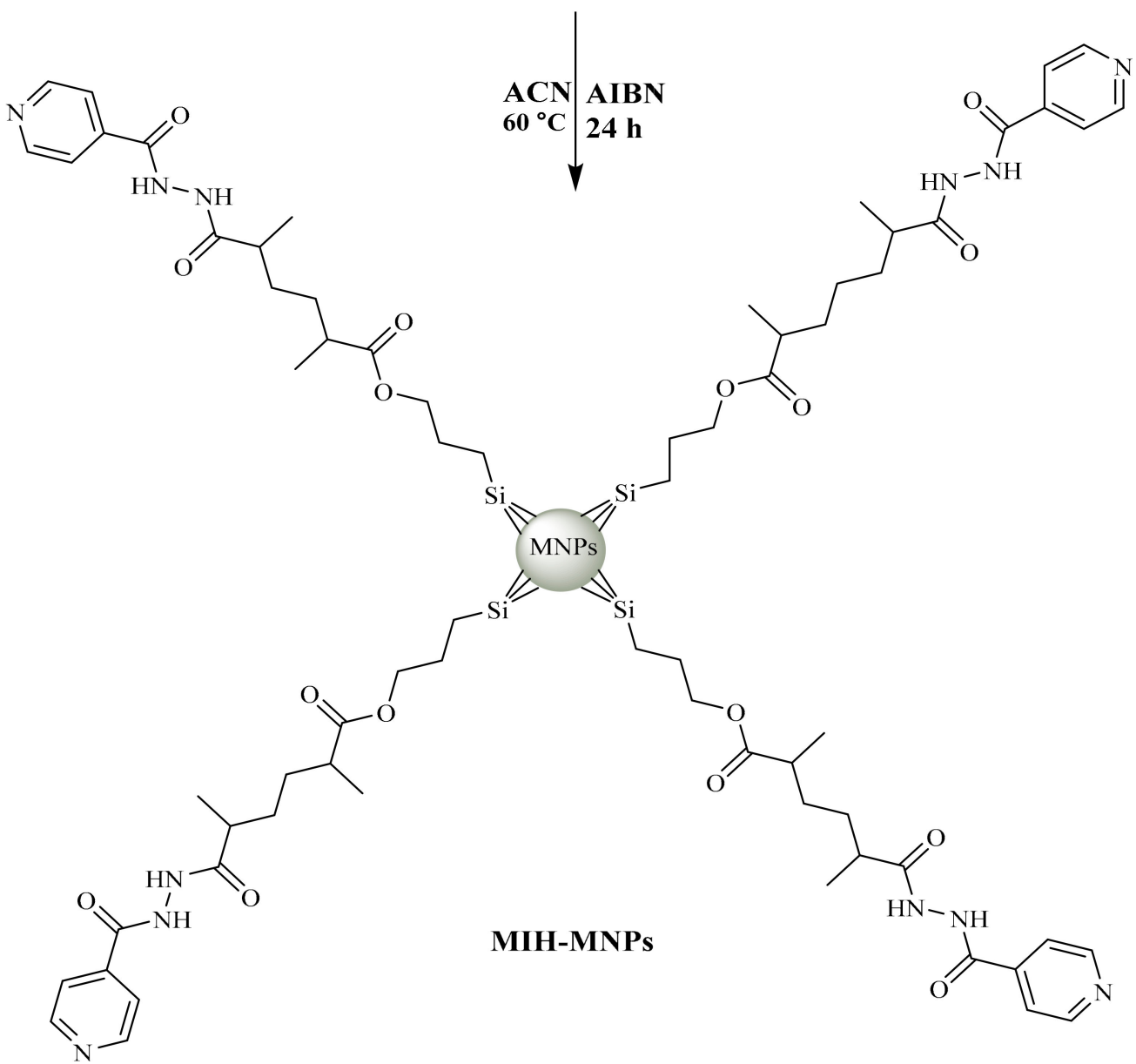

Figure 1. Synthetic scheme of MIH and MIH coated magnetic nanoparticles (MIH-MNPs) [28]. 


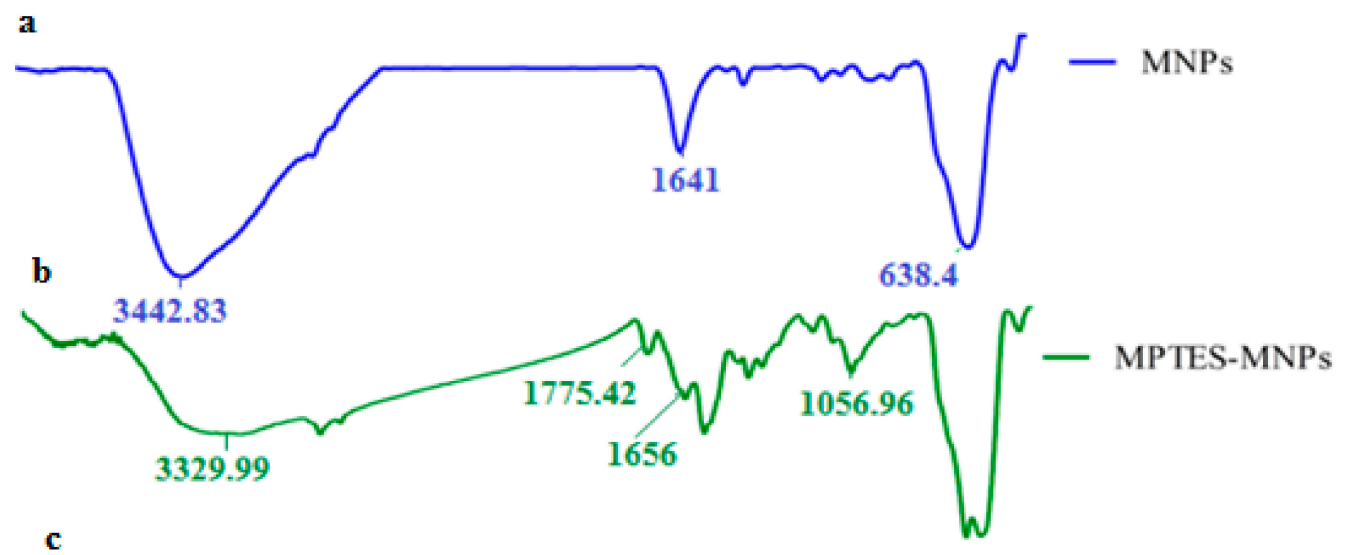

c
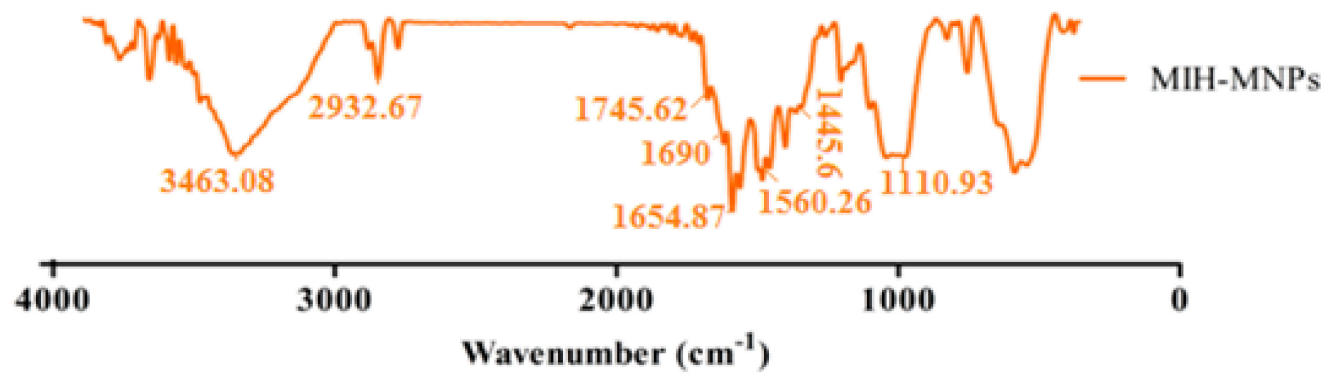

Figure 2. (a) Fourier transformed infrared spectroscopic (FTIR) spectra of magnetite nano particle, (b) spectra of silane coated nano particle, and (c) spectra of synthesized MIH-MNPs.

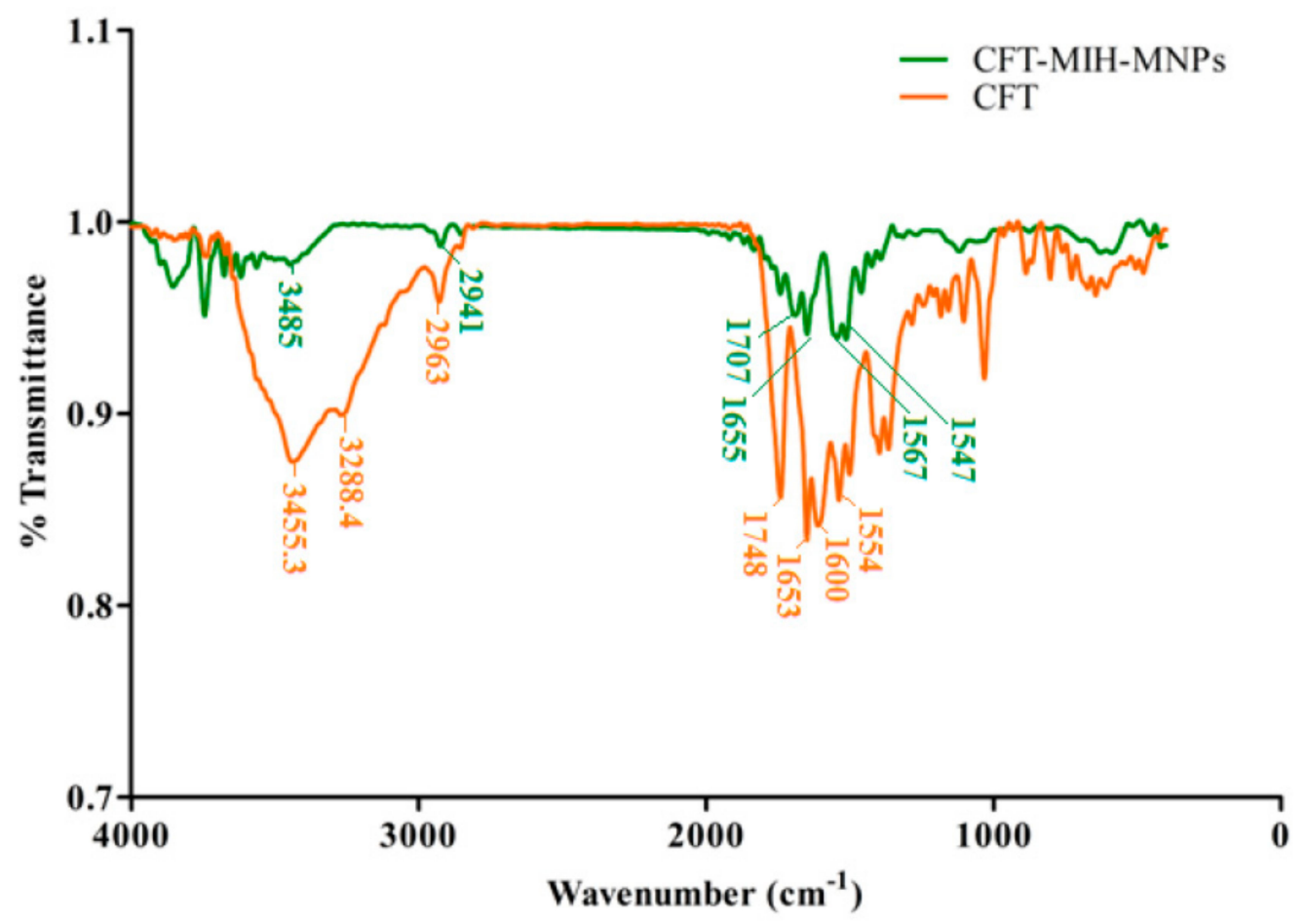

Figure 3. FTIR spectra of drug-loaded CFT-MIH-MNPs along with ceftriaxone.

\subsection{Particle Size, Size Distribution, Zeta Potential and Morphology Studies}

Dynamic light scattering (DLS) technique showed an average hydrodynamic diameter of $168.0 \pm$ $7.3 \mathrm{~nm}$ and $184.0 \pm 2.7 \mathrm{~nm}$ for MIH-MNPs and CFT-MIH-MNPs, respectively. Thus, the incorporation of CFT onto the surface of NPs increased the size of the MNPs. Zeta potential of MNPs was found to be $-11.4 \pm 1.32 \mathrm{mV}$, and upon fabrication with an MIH molecule, the zeta potential intensity increased 
to $-17.7 \pm 0.40 \mathrm{mV}$, indicating successful conjugation of MIH onto the surface of MNPs. When CFT was introduced, the zeta potential further increased to $-20.2 \pm 0 . \mathrm{mV}$ (Table 1), indicating binding of CFT onto the surface of MNPs. The studies were performed at neutral $\mathrm{pH}(\mathrm{pH}=7.4)$. Higher zeta potential may indicate better colloidal stability which was the case when the drug was hosted by MIH-MNPs. This assumption was validated further under various conditions in subsequent studies within this report. The polydispersity index (PDI) describes the uniform dispersion of colloidal suspension. PDI values higher than 0.3 indicate polydispersity of the particles [33]. In our study, the PDI of drug-free and CFT-loaded MIH-MNPs were found to be 0.237 and 0.265 (Table 1), respectively, indicating NPs homogeneity. AFM images showed a nearly spherical shape of the MIH-MNPs, which became slightly distorted after drug incorporation, possibly due to filling of hollow matrices within the NPs (Figure 4). Moreover, an AFM image showed uniform size distribution of drug-loaded NPs, supporting PDI findings (Table 1).

Table 1. Characteristics of CFT-MIH-MNPs formulation (average size, PDI and drug entrapment efficiency).

\begin{tabular}{ccccc}
\hline Sample & $\begin{array}{c}\text { Average Size } \\
\mathbf{( n m )}\end{array}$ & $\begin{array}{c}\text { Polydispersity } \\
\text { Index (PDI) }\end{array}$ & $\begin{array}{c}\text { Zeta Potential } \\
\mathbf{( m V )}\end{array}$ & $\begin{array}{c}\text { Drug Entrapment } \\
\text { Efficiency (\%) }\end{array}$ \\
\hline MPTES-MNPs & $124 \pm 3.4$ & 0.232 & $-11.4 \pm 1.3$ & - \\
\hline CFT-MPTES-MNPs & $143 \pm 5.9$ & 0.252 & $-18.3 \pm 0.2$ & $73.1 \pm 2.4$ \\
\hline MIH-MNPs & $168 \pm 7.3$ & 0.237 & $-17.7 \pm 0.4$ & - \\
CFT-MIH-MNPs & $184 \pm 2.7$ & 0.265 & $-20.2 \pm 0.4$ & $79.4 \pm 1.5$ \\
\hline
\end{tabular}
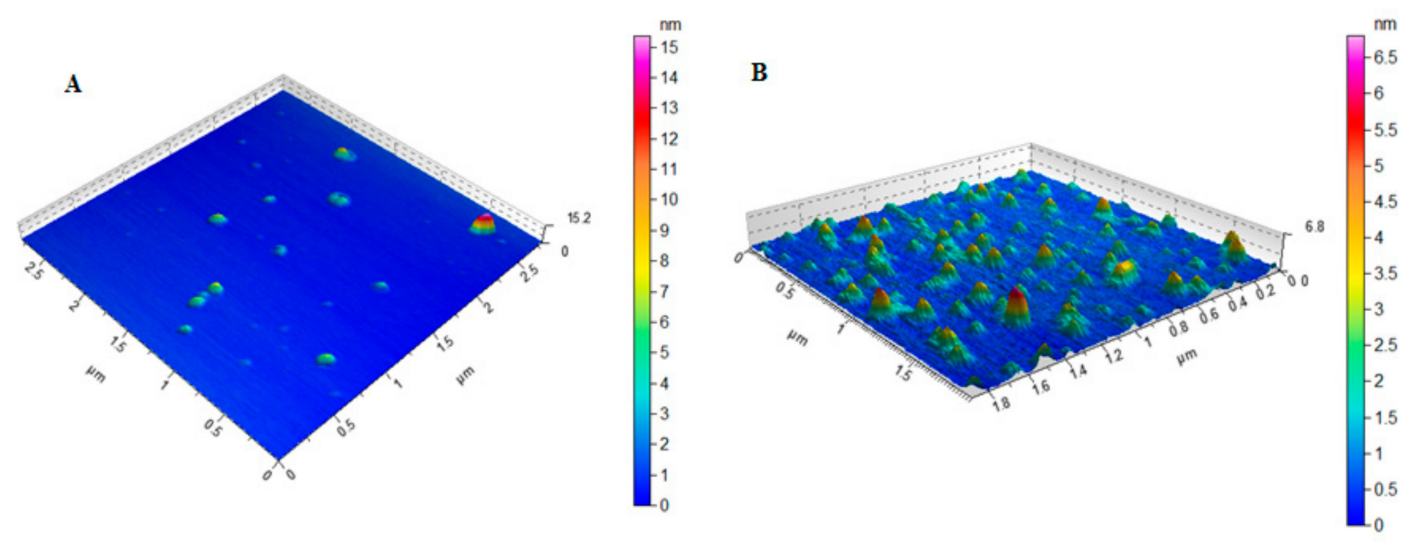

Figure 4. AFM images of (A) MIH-MNPs and(B) CFT-MIH-MNPs.

\subsection{Stability in Simulated Gastric Fluids (SGF)}

Targeting intestinal delivery requires stability in a gastric environment. IONPs are greatly influenced by ionic strength and $\mathrm{pH}$ of the medium [34]. Synthetic gastrointestinal environment was developed in vitro to evaluate the stability of MIH-MNPs and CFT-MIH-MNPs for $72 \mathrm{~h}$. The outcome of the study showed prominent stability of MIH-MNPs and CFT-MIH-MNPs under a gastric environment (i.e., size and PDI remained under 15\% variation), which was due to the inherent high zeta potential and surface functionalized pyridine moiety. This tends to protonate at a low $\mathrm{pH}$ and give rise to electrostatic repulsion between the NPs, which contributes to stabilizing the particles under the simulated gastric environment (Figure 5A,B). Intestinal stability was evaluated by incubating MNPs in synthetic intestinal fluid, prepared without enzymes and in lysosomal fluid. Particle size and PDI of MIH-MNPs and CFT-MIH-MNPs remained unchanged, indicating nanoparticle stability in the intestinal environment (Figure 5C,D). 

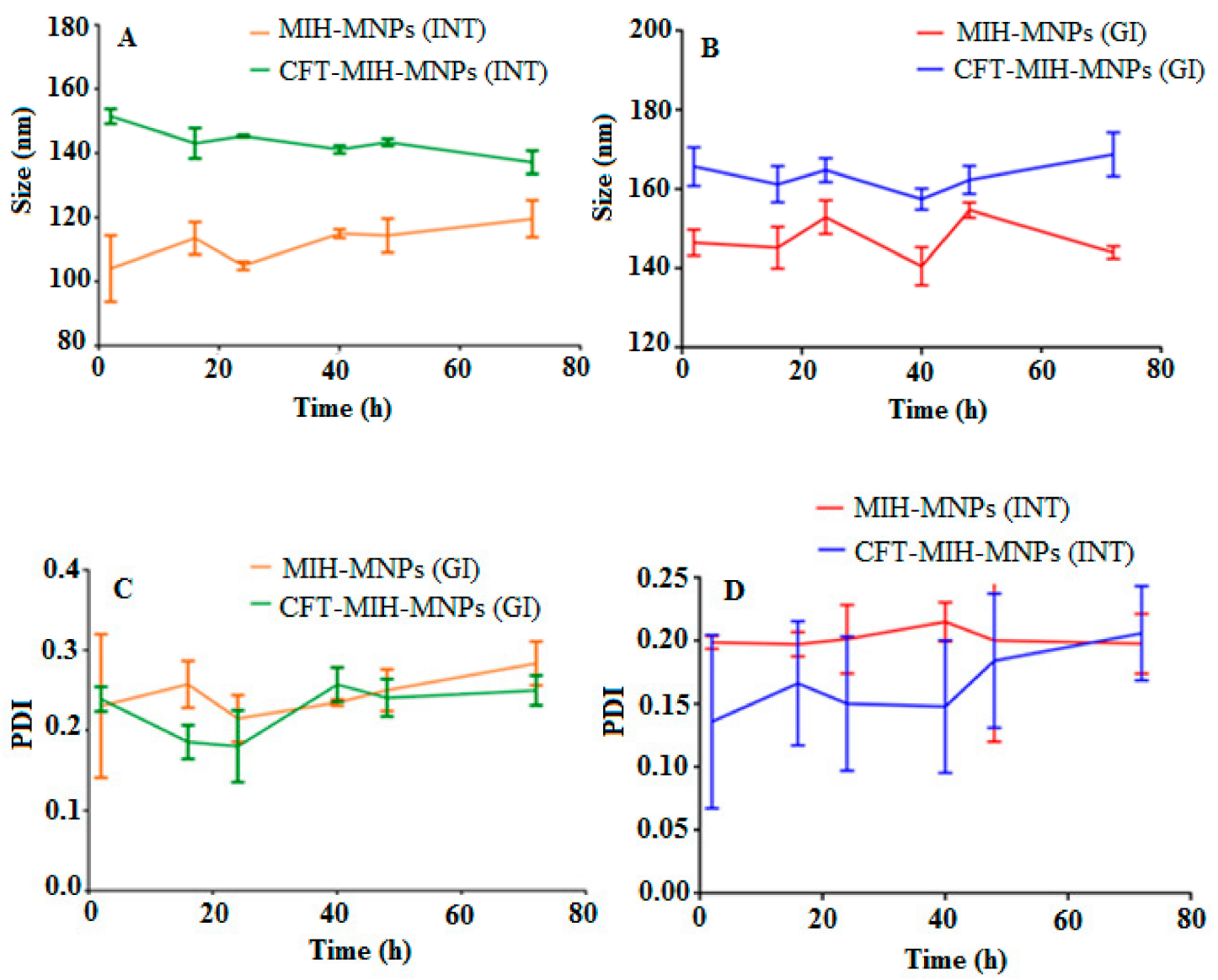

Figure 5. Hydrodynamic diameter of MIH-MNPs and CFT-MIH-MNPs under GIT conditions (A,B). PDI of MIH-MNPs and CFT-MIH-MNPs under GIT conditions (C,D).

\subsection{Development of HPLC Protocol for the Determination of CFT in Blood Plasma}

In order to investigate the concentration of CFT in blood after administration of CFT-MIH-MNPs in vivo, the HPLC method was developed and validated for the determination of CFT in blood plasma. The optimized procedure indicated stability within three freeze-thaw cycles owing to acceptable variations in results (from $90.6 \%$ to $110 \%$ ). The retention time of CFT and CEP was found to be 13.5 and $8.5 \mathrm{~min}$, respectively. The developed method showed an excellent linear relationship with an $\mathrm{R}^{2}$ value of 0.998 over a concentration range of $1-50 \mu \mathrm{g} / \mathrm{mL}$ of CFT in blood plasma. The method was validated as inaccuracy $(\% \mathrm{CV}=2.60 \%)$ and precision $(\% \mathrm{CV}=1.9 \%)$ were well within compliance limits.

\subsection{Drug Entrapment Efficiency}

One of the most significant properties of a nanocarrier is its ability to act as a delivery system by accommodating the drug and transporting it to the desired site/organ, eventually being able to release the drug over a prolonged period. CFT consists of weak acidic molecules with a pKa of 3, 3.2 and 4.1 and an early neutral pH of about 6.7 [35]. The entrapment efficiency of CFT-MIH-MNPs was found to be $79.4 \% \pm 1.5 \%$ in comparison to $73.13 \% \pm 2.4 \%$ of drug-loaded MPTES-MNPs. The slight increase in drug loading may be attributed to increased secondary interactions in terms of pi-pi stacking, and increased hydrogen bonding offered by a coated MIH molecule (Figure 6). As shown in Table 1, the surface charge of drug-free MIH-MNPs was negative at a neutral $\mathrm{pH}$ medium. Thus, the secondary electrostatic interaction and chelation between MIH-MP and CFT could be the mechanism of drug entrapment [36]. Increment in zeta potential demonstrated the effective drug hosting as the drug binds to NPs. The negatively charged core tends to interact more strongly with the drug, owing to its lowered pKa, which may make MIH-MNPs a useful supramolecular hosting system for provision of 
significant entrapment of CFT. CFT entrapment values found in our study are higher than entrapment reported using other nanocarriers such as chitosan NPs in which the proportion of drug entrapped was dependent on drug concentration (EE up to50\%) [30].

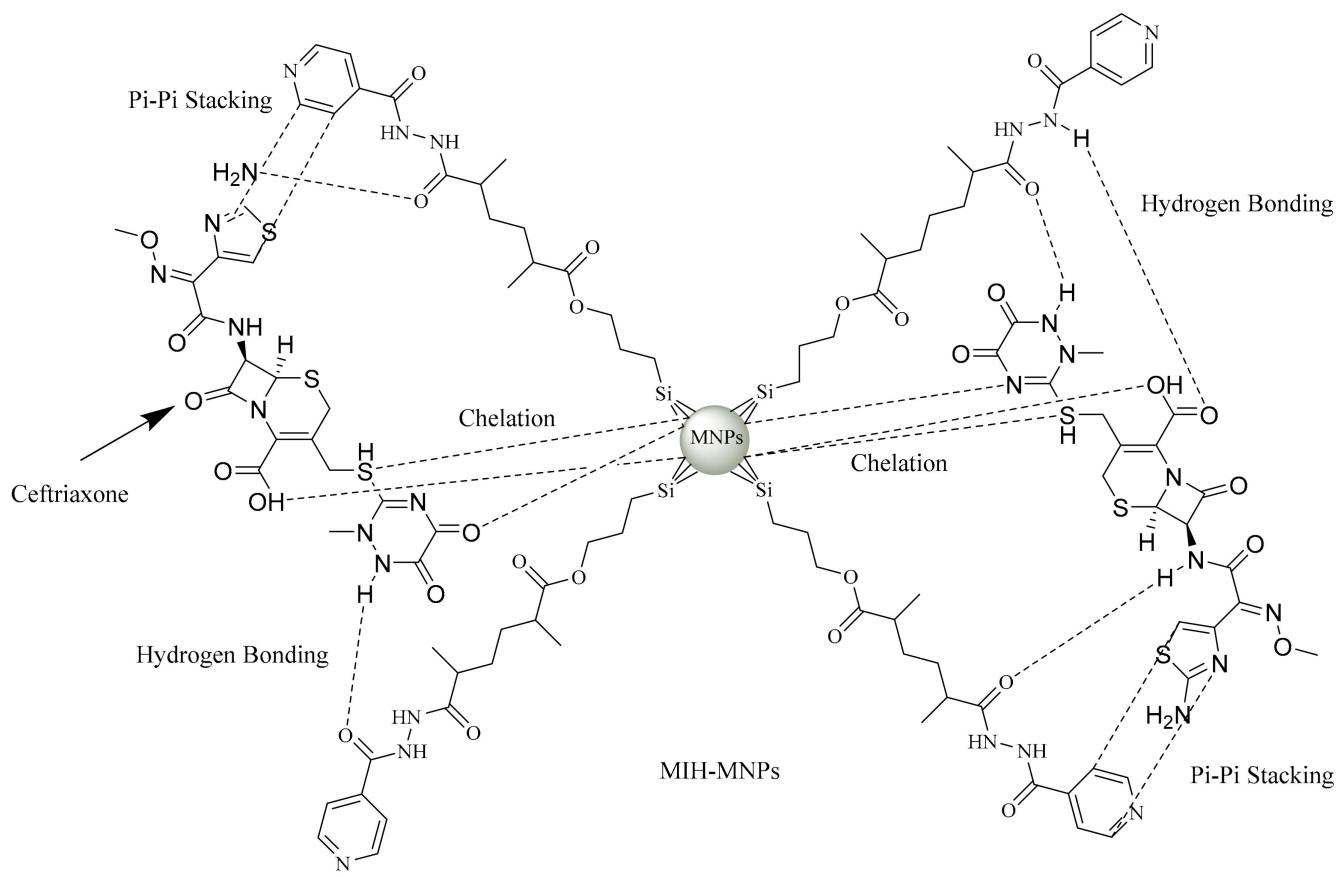

Figure 6. Aschematic diagram demonstrating the various possible interactionsbetweenceftriaxone (CFT) and MIH-MNPs.

\subsection{In Vitro Drug Release Study}

The release profile of CFT molecules from MIH-MNPs analogue was estimated at a physiological $\mathrm{pH}$ of 7.4 and a weakly acidic environment of $\mathrm{pH} 4.0$, under maintained physiological temperature (Figure 7). Interestingly, CFT-MIH-MNPs show a higher release of $24.3 \% \pm 1.5 \%$ at $\mathrm{pH} 7.4$ in comparison with $\mathrm{pH} 4.0$, being $18.89 \% \pm 0.3 \%$ at $6 \mathrm{~h}$. The lower drug release at an acidic $\mathrm{pH}$ may be attributed to protonation of the pyridinium nitrogen, which promotes the electrostatic interactions between CFT and NPs. The higher release at physiological $\mathrm{pH}$ (i.e., $\mathrm{pH}$ 7.4) may support our hypothesis of stabilization of CFT molecules in acidic $\mathrm{pH}$ [37].

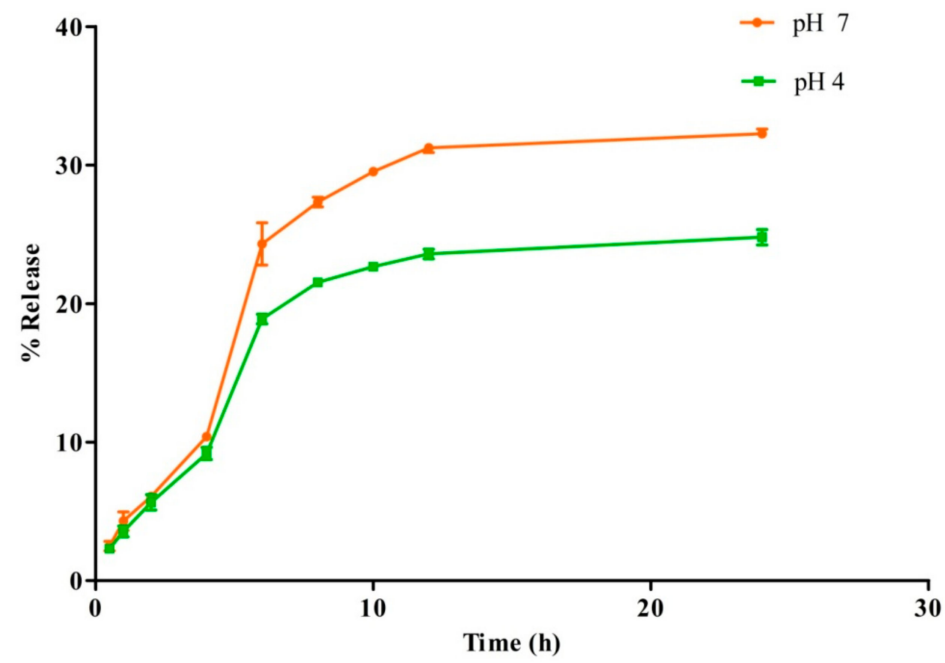

Figure 7. In vitro release profile of CFT-MIH-MNPs formulation at different $\mathrm{pH}$ values. 


\subsection{Hemocompatibility}

The interaction of surface-functionalized magnetic NPs with negatively charged membranes was studied via the hemolysis test [38]. The hemolytic effects of MIH-MNPs were performed at five different concentrations $(200,400,600,800$ and $1000 \mu \mathrm{g} / \mathrm{mL})$ against triton $X$ as a positive control, and the released hemoglobin was quantitatively analyzed at $541 \mathrm{~nm}$ (Figure 8a). When the concentration was $1 \mathrm{mg} / \mathrm{mL}$, the hemolytic activity was less than $10 \%$ which suggests blood compatibility findings [37,39] and encouraged us to proceed with subsequent in vitro and in vivo studies.
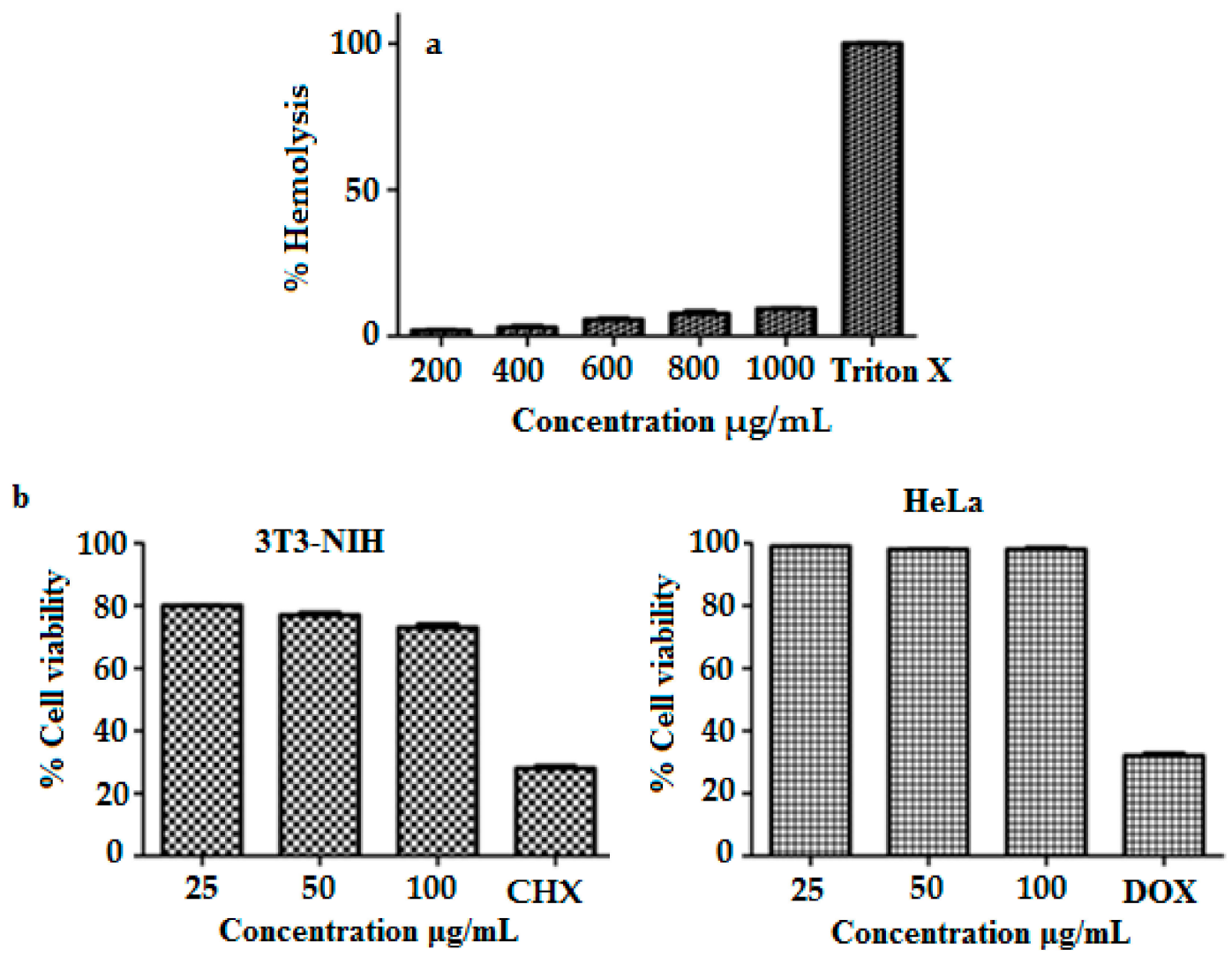

Figure 8. (a) Percent hemolysis of MIH-MP nano particle at different concentration. (b) In vitrocytotoxicity profile of MIH-MP nano particles against 3T3(NIH) and HeLa cell lines.

\subsection{In Vitro Cytotoxicity}

Although MNPs are well reported for biomedical applications, it is essential to perform cytotoxic analysis to evaluate safety of the designed MNPs [25]. The mitochondrial deterioration within the cellular core after uptake of MNPs was studied using the MTT method. The cytotoxicity of designed MNPs was evaluated in a dose-dependent manner (Figure 8b), and shows the findings of cell viability of MIH-MNPs against 3T3 and Hela cell lines after $48 \mathrm{~h}$. Results show that 3T3 cell lines demonstrate a dose-dependent biocompatibility. Cell viability at $100 \mu \mathrm{g} / \mathrm{mL}$ was found to be $73.0 \% \pm 1.2 \%$, which in comparison, shows higher viability than what was previously reported for MNPs [40]. The decrease in cellular viability of 3T3 may be attributed to the production of reactive oxygen species (ROS) upon MIH-MNPs uptake [41]. However, higher biocompatibility was observed in the case of Hela cell lines, which was found to be $98.0 \% \pm 0.2 \%$, respectively. Biocompatibility within less than $100 \mu \mathrm{g} / \mathrm{mL}$ encourages exploring MIH-MNPs for in vivo applications. 


\subsection{In Vivo Oral Pharmacokinetic Studies}

CFT plasma concentrations curve at various time intervals after oral dosing in the form of its solution $(50 \mathrm{mg} / \mathrm{kg}$ ) and CFT-MIH-MNPs formulation $(25 \mathrm{mg} / \mathrm{kg})$ are shown in Figure 9. Pharmacokinetics parameters were evaluated from plasma concentrations versus time plot and are detailed in Table 2 . The maximum plasma concentration $\left(\mathrm{C}_{\max }\right)$ of $14.4 \pm 1.8 \mu \mathrm{g} / \mathrm{mL}$ was achieved for $25 \mathrm{mg} / \mathrm{kg} \mathrm{dose}$ at $6 \mathrm{~h}$ when CFT was entrapped in MIH-MNPs, with reference to its control which was found to be $2.0 \pm 0.6 \mu \mathrm{g} / \mathrm{mL}$ for a $50 \mathrm{mg} / \mathrm{kg}$ dose at $1.5 \mathrm{~h}$. This was in agreement with previously published studies [42]. In our in vivo experiments, no drug was detected in HPLC chromatograms when the control CFT was administered at $25 \mathrm{mg} / \mathrm{kg}$. This is attributed to the acid-labile property and low penetration nature of CFT when given in a traditional solution form [43]. This provided evidence that our MNPs formulation protected CFT from degradation in the acidic environment of the stomach owing to electrostatic interaction between protonated pyridine moiety and negative CFT molecule, which is further supported by the fact that CFT-MIH-MNPs formulation was stable in the simulated gastric fluid, as shown earlier in Section 3.4.

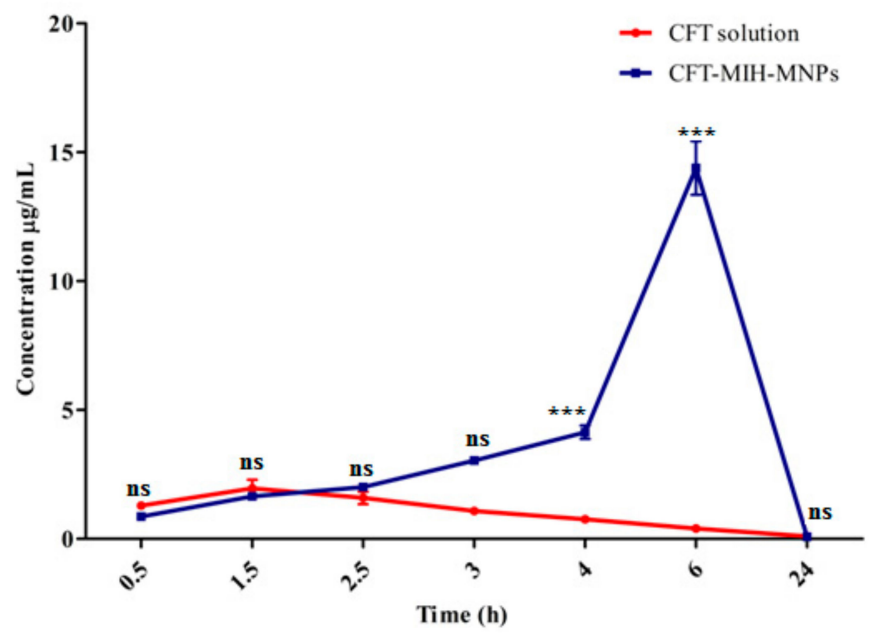

Figure 9. In vivo profile of CFT-MIH-MNPs against oral control at ${ }^{* * *}$ extremelysignificant $(p<0.001)$, ${ }^{* *}$ highly significant $(p<0.01),{ }^{*}$ significant $(p<0.05),{ }^{\text {ns }}$ not significant $(p>0.05)$.

Table 2. In vivo oral pharmacokinetic parameters when administered CFT-MIH-MNPs loaded formulation, oral control and intravenous control.

\begin{tabular}{ccc}
\hline Pharmacokinetic Parameters & CFT Solution & CFT-MIH-MNPs Formulation \\
\hline Dose $(\mathrm{mg} / \mathrm{kg})$ & $50.0 \pm 0.3$ & $25.0 \pm 0.3$ \\
$\mathrm{C}_{\max }(\mu \mathrm{g} / \mathrm{mL})$ & $2.0 \pm 0.6$ & $14.4 \pm 1.8^{* * *}$ \\
$\mathrm{AUC}_{0-24}(\mu \mathrm{g} \cdot \mathrm{h} / \mathrm{mL})$ & $16.1 \pm 3.7$ & $156.8 \pm 0.3^{* * *}$ \\
$\mathrm{MRT}(\mathrm{h})$ & $8.4 \pm 0.1$ & $12.2 \pm 0.2^{* * *}$ \\
$\mathrm{~T}_{\max }(\mathrm{h})$ & 1.5 & 6 \\
Clearance $(\mathrm{L} / \mathrm{h})$ & $3.9 \pm 0.4$ & $1.6 \pm 0.2^{* * *}$ \\
Volume distribution $(\mathrm{L})$ & $33.0 \pm 1.94$ & $10.9 \pm 2.4^{* *}$ \\
\hline${ }^{* * *}$ Ex $^{* *}$ &
\end{tabular}

Interestingly, the minimal dose of $25 \mathrm{mg} / \mathrm{kg}$ in the form of CFT-MIH-MNPs enhanced the $\mathrm{C}_{\max }$ by 7.2 fold and $T_{\max }$ to $6 \mathrm{~h}$. This is significantly higher with reference to its control, which at the same dosage showed no detection of CFT in the blood plasma. Moreover, the CFT-MIH-MNPs formulation showed in vivo resistance represented by a mean residence time (MRT) of $12.2 \pm 0.2 \mathrm{~h}$ and decreased clearance of $1.6 \pm 0.2 \mathrm{~L} / \mathrm{h}$, in comparison to the control which had values of $8.4 \pm 0.1 \mathrm{~h}$ and $3.91 \pm 0.4 \mathrm{~L} / \mathrm{h}$, respectively. This shows the stability and sustainability of CFT-MIH-MNPs formulation caused by 
the significant increase in drug plasma concentration arising from the higher absorption of the drug through GIT [44].

The nano size and negative surface charge also enhances the lymphatic drainage across the intestine [45]. Furthermore, the drug entrapped in magnetic NPs can prevent its degradation in the harsh acidic environment $[46,47]$. Nanoformulation may help by passing the first-pass hepatic metabolism and enterohepatic circulation by passing through portal circulation [48], thereby enhancing oral absorption. Compounds rich in $\mathrm{OH}$ and $\mathrm{NH}_{2}$ functional moieties may possess bioadhesive properties [49]. Bio adhesive functional moieties, stability in a harsh gastric environment, minimization of first-pass metabolism and negative surface charge of the NPs are all potential contributors to the enhancement of oral absorption of CFT across the GIT epithelium.

Finally, reflecting on the procedure used to prepare CFT-MIH-MNPs, another antibiotic (isoniazid) was employed to stabilize CFT. It is well known that antibiotic drug combinations may elicit additional or synergistic therapeutic effects but may also result in a higher potential of antibiotic resistance. An enhanced antibacterial effect has been reported by combining cefotaxime (another third generation cephalosporin) with isoniazid and rifampicin [50]. Future investigations may explore the potential benefit or harm of using isoniazid in the chemical composition of the present MNP formulation in vitro and in vivo. Furthermore, our research group will consider conducting studies to explore more directions related to the use of MNPs, such as the role of MNPs as acoustic imaging tools [51].

\section{Conclusions}

We have designed a biocompatible MIH conjugated IONPs to enhance stability and permeability of CFT across the GIT epithelium. The NPs were found to be highly biocompatible, showing good GIT persistence and the ability to entrap therapeutic proportions of the drug. The developed MIH-MNPs formulation considerably enhanced the in vivo oral bioavailability of CFT with reference to its control using an animal model. This study suggests that the resulting nano range carrier can be a promising strategy for enhancing the oral bioavailability of low penetrating and unstable drugs across the GIT epithelium, taking the CFT model as a successful example.

Author Contributions: This research has been conceptualized and designed by M.K., and M.R.S., with valuable contributions from the rest of the authors. Experimental study was conducted by M.K., T.J., K.M.I., and H.Z., under the supervision of M.R.S., Data investigation was performed by M.K., T.J., and K.M.I., M.R.S., provided materials, equipments and lab for the experiments and M.K., wrote the manuscript which was further proof read by A.B.E., and M.R.S. All authors have read and agreed to the published version of the manuscript.

Funding: The research receives no external funding.

Acknowledgments: All the authors acknowledge H.E.J research institute of chemistry International Centre of Chemical and Biological Sciences University of Karachi-75270 Pakistan.

Conflicts of Interest: All the authors declare no conflict of interests.

\section{References}

1. Huang, J.; Shu, Q.; Wang, L.; Wu, H.; Wang, A.Y.; Mao, H. Layer-by-layer assembled milk protein coated magnetic nanoparticle enabled oral drug delivery with high stability in stomach and enzyme-responsive release in small intestine. Biomaterials 2015, 39, 105-113. [CrossRef] [PubMed]

2. Thanki, K.; Gangwal, R.P.; Sangamwar, A.T.; Jain, S. Oral delivery of anticancer drugs: Challenges and opportunities. J. Control. Release 2013, 170, 15-40. [CrossRef] [PubMed]

3. Gamboa, J.M.; Leong, K.W. In vitro and in vivo models for the study of oral delivery of nanoparticles. Adv. Drug Deliv. Rev. 2013, 65, 800-810. [CrossRef] [PubMed]

4. Leong, K.W.; Sung, H.-W. Nanoparticle-and biomaterials-mediated oral delivery for drug, gene, and immunotherapy. Adv. Drug Deliv. Rev. 2013, 65, 757-758. [CrossRef]

5. Chomoucka, J.; Drbohlavova, J.; Huska, D.; Adam, V.; Kizek, R.; Hubalek, J. Magnetic nanoparticles and targeted drug delivering. Pharmacol. Res. 2010, 62, 144-149. [CrossRef] 
6. Shete, H.K.; Vyas, S.S.; Patravale, V.B.; Disouza, J.I. Pulmonary multifunctional nano-oncological modules for lung cancer treatment and prevention. J. Biomed. Nanotechnol. 2014, 10, 1863-1893. [CrossRef]

7. Santana, S.D.; Dhadge, V.L.; Roque, A.C. Dextran-coated magnetic supports modified with a biomimetic ligand for IgG purification. ACS Appl. Mater. Interfaces 2012, 4, 5907-5914. [CrossRef]

8. Arruebo, M.; Fernández-Pacheco, R.; Ibarra, M.R.; Santamaría, J. Magnetic nanoparticles for drug delivery. Nano Today 2007, 2, 22-32. [CrossRef]

9. Yuan, Q.; Venkatasubramanian, R.; Hein, S.; Misra, R. A stimulus-responsive magnetic nanoparticle drug carrier: Magnetite encapsulated by chitosan-grafted-copolymer. Acta Biomater. 2008, 4, 1024-1037. [CrossRef]

10. Chen, J.-P.; Yang, P.-C.; Ma, Y.-H.; Wu, T. Characterization of chitosan magnetic nanoparticles for in situ delivery of tissue plasminogen activator. Carbohydr. Polym. 2011, 84, 364-372. [CrossRef]

11. Zhang, J.; Misra, R. Magnetic drug-targeting carrier encapsulated with thermosensitive smart polymer: Core-shell nanoparticle carrier and drug release response. Acta Biomater. 2007, 3, 838-850. [CrossRef] [PubMed]

12. Kebede, A.; Singh, A.K.; Rai, P.K.; Giri, N.K.; Rai, A.K.; Watal, G.; Gholap, A. Controlled synthesis, characterization, and application of iron oxide nanoparticles for oral delivery of insulin. Lasers Med Sci. 2013, 28, 579-587. [CrossRef] [PubMed]

13. Kansy, M.; Senner, F.; Gubernator, K. Physicochemical high throughput screening: Parallel artificial membrane permeation assay in the description of passive absorption processes. J. Med. Chem. 1998, 41, 1007-1010. [CrossRef] [PubMed]

14. Shaikh, M.; Derle, N.D.; Bhamber, R. Permeability enhancement techniques for poorly permeable drugs: A review. J. Appl. Pharm. Sci. 2012, 2, 34-39. [CrossRef]

15. Lee, S.; Kim, S.K.; Lee, D.Y.; Park, K.; Kumar, T.S.; Chae, S.Y.; Byun, Y. Cationic analog of deoxycholate as an oral delivery carrier for ceftriaxone. J. Pharm. Sci. 2005, 94, 2541-2548. [CrossRef] [PubMed]

16. Dresco, P.A.; Zaitsev, V.S.; Gambino, R.J.; Chu, B. Preparation and properties of magnetite and polymer magnetite nanoparticles. Langmuir 1999, 15, 1945-1951. [CrossRef]

17. Saif, B.; Wang, C.; Chuan, D.; Shuang, S. Synthesis and characterization of Fe3O4 coated on APTES as carriers for morin-anticancer drug. J. Biomater. Nanobiotechnol. 2015, 6, 267. [CrossRef]

18. Pan, Q.; Lv, Y.; Williams, G.R.; Tao, L.; Yang, H.; Li, H.; Zhu, L. Lactobionic acid and carboxymethyl chitosan functionalized graphene oxide nanocomposites as targeted anticancer drug delivery systems. Carbohydr. Polym. 2016, 151, 812-820. [CrossRef]

19. Lazzari, S.; Moscatelli, D.; Codari, F.; Salmona, M.; Morbidelli, M.; Diomede, L. Colloidal stability of polymeric nanoparticles in biological fluids. J. Nanoparticle Res. 2012, 14, 920. [CrossRef]

20. Date, A.A.; Nagarsenker, M.S.; Patere, S.; Dhawan, V.; Gude, R.; Hassan, P.; Aswal, V.; Steiniger, F.; Thamm, J.; Fahr, A. Lecithin-based novel cationic nanocarriers (Leciplex) II: Improving therapeutic efficacy of quercetin on oral administration. Mol. Pharm. 2011, 8, 716-726. [CrossRef]

21. Wang, Y.; Wang, S.; Firempong, C.K.; Zhang, H.; Wang, M.; Zhang, Y.; Zhu, Y.; Yu, J.; Xu, X. Enhanced solubility and bioavailability of naringenin via liposomal nanoformulation: Preparation and in vitro and in vivo evaluations. AAPS Pharmscitech 2017, 18, 586-594. [CrossRef] [PubMed]

22. Rodrigues, M.O.; Cantos, J.B.; D'Oca, C.R.M.; Soares, K.L.; Coelho, T.S.; Piovesan, L.A.; Russowsky, D.; da Silva, P.A.; D'Oca, M.G.M. Synthesis and antimycobacterial activity of isoniazid derivatives from renewable fatty acids. Bioorg. Med. Chem. 2013, 21, 6910-6914. [CrossRef] [PubMed]

23. Sutar, Y.B.; Mali, J.K.; Telvekar, V.N.; Rajmani, R.S.; Singh, A. Transferrin conjugates of antitubercular drug isoniazid: Synthesis and in vitro efficacy. Eur. J. Med. Chem. 2019, 183, 111713. [CrossRef] [PubMed]

24. Valeur, E.; Bradley, M. Amide bond formation: Beyond the myth of coupling reagents. Chem. Soc. Rev. 2009, 38, 606-631. [CrossRef]

25. Santos, M.; Seabra, A.; Pelegrino, M.; Haddad, P. Synthesis, characterization and cytotoxicity of glutathione-and PEG-glutathione-superparamagnetic iron oxide nanoparticles for nitric oxide delivery. Appl. Surf. Sci. 2016, 367, 26-35. [CrossRef]

26. Raliya, R. Nanoscale Engineering in Agricultural Management; CRC Press: Boca Raton, FL, USA, 2019.

27. Jiao, F.; Gao, F.; Wang, H.; Deng, Y.; Zhang, Y.; Qian, X.; Zhang, Y. Polymeric hydrophilic ionic liquids used to modify magnetic nanoparticles for the highly selective enrichment of N-linked glycopeptides. Sci. Rep. 2017, 7, 6984. [CrossRef]

28. Petcharoen, K.; Sirivat, A. Synthesis and characterization of magnetite nanoparticles via the chemical co-precipitation method. Mater. Sci. Eng. B 2012, 177, 421-427. [CrossRef] 
29. Arsalani, N.; Fattahi, H.; Nazarpoor, M. Synthesis and characterization of PVP-functionalized superparamagnetic $\mathrm{Fe}_{3} \mathrm{O}_{4}$ nanoparticles as an MRI contrast agent. Express Polym. Lett. 2010, 4, 329-338. [CrossRef]

30. Zaki, N.M.; Hafez, M.M. Enhanced antibacterial effect of ceftriaxone sodium-loaded chitosan nanoparticles against intracellular Salmonella typhimurium. AAPS Pharmscitechnol. 2012, 13, 411-421. [CrossRef]

31. Chandra, D.; Kohli, G.; Prasad, K.; Bisht, G.; Punetha, V.D.; Khetwal, K.; Devrani, M.K.; Pandey, H. Phytochemical and Ethnomedicinal Uses of Family Violaceae. Curr. Res. Chem. 2015, 7, 44-52. [CrossRef]

32. Hasanova, U.; Ramazanov, M.; Maharramov, A.; Gakhramanova, Z.; Hajiyeva, S.; Eyvazova, Q.; Vezirova, L.; Hajiyeva, F.; Hasanova, M.; Guliyeva, N. Synthesis of Macrocycle (MC)-Mimics the Properties of Natural Siderophores and Preparation the Nanostructures on the Basis of MC and Magnetite Nanoparticles. Chem. Eng. Trans. 2016, 47, 109-114.

33. Caddeo, C.; Teskač, K.; Sinico, C.; Kristl, J. Effect of resveratrol incorporated in liposomes on proliferation and UV-B protection of cells. Int. J. Pharm. 2008, 363, 183-191. [CrossRef] [PubMed]

34. Yang, S.-C.; Paik, S.-Y.-R.; Ryu, J.; Choi, K.-O.; Kang, T.S.; Lee, J.K.; Song, C.W.; Ko, S. Dynamic light scattering-based method to determine primary particle size of iron oxide nanoparticles in simulated gastrointestinal fluid. Food Chem. 2014, 161, 185-191. [CrossRef] [PubMed]

35. Sun, H.; Wang, H.; Ge, X. Simultaneous determination of the combined drugs of ceftriaxone sodium, metronidazole, and levofloxacin in human urine by high-performance liquid chromatography. J. Clin. Lab. Anal. 2012, 26, 486-492. [CrossRef]

36. Gaihre, B.; Khil, M.S.; Lee, D.R.; Kim, H.Y. Gelatin-coated magnetic iron oxide nanoparticles as carrier system: Drug loading and in vitro drug release study. Int. J. Pharm. 2009, 365, 180-189. [CrossRef]

37. Beskid, G.; Unowsky, J.; Behl, C.R.; Siebelist, J.A.; Tossounian, J.L.; McGarry, C.M.; Shah, N.H.; Cleeland, R. Enteral, oral, and rectal absorption of ceftriaxone using glyceride enhancers. Chemotherapy 1988, 34, 77-84. [CrossRef]

38. Fischer, D.; Li, Y.; Ahlemeyer, B.; Krieglstein, J.; Kissel, T. In vitro cytotoxicity testing of polycations: Influence of polymer structure on cell viability and hemolysis. Biomaterials 2003, 24, 1121-1131. [CrossRef]

39. Dobrovolskaia, M.A.; Clogston, J.D.; Neun, B.W.; Hall, J.B.; Patri, A.K.; McNeil, S.E. Method for Analysis of Nanoparticle Hemolytic Properties in Vitro. Nano Lett. 2008, 8, 2180-2187. [CrossRef]

40. Seabra, A.B.; Pasquoto, T.; Ferrarini, A.C.F.; Santos, M.d.C.; Haddad, P.S.; de Lima, R. Preparation, characterization, cytotoxicity, and genotoxicity evaluations of thiolated-and S-nitrosated superparamagnetic iron oxide nanoparticles: Implications for cancer treatment. Chem. Res. Toxicol. 2014, 27, 1207-1218. [CrossRef]

41. Laurent, S.; Forge, D.; Port, M.; Roch, A.; Robic, C.; Vander Elst, L.; Muller, R.N. Magnetic iron oxide nanoparticles: Synthesis, stabilization, vectorization, physicochemical characterizations, and biological applications. Chem. Rev. 2008, 108, 2064-2110. [CrossRef]

42. Jeon, O.-C.; Hwang, S.R.; Al-Hilal, T.A.; Park, J.W.; Moon, H.T.; Lee, S.; Park, J.H.; Byun, Y. Oral delivery of ionic complex of ceftriaxone with bile acid derivative in non-human primates. Pharm. Res. 2013, 30, 959-967. [CrossRef] [PubMed]

43. Cho, S.-W.; Lee, J.S.; Choi, S.-H. Enhanced oral bioavailability of poorly absorbed drugs. I. Screening of absorption carrier for the ceftriaxone complex. J. Pharm. Sci. 2004, 93, 612-620. [CrossRef] [PubMed]

44. Siu, F.Y.; Ye, S.; Lin, H.; Li, S. Galactosylated PLGA nanoparticles for the oral delivery of resveratrol: Enhanced bioavailability and in vitro anti-inflammatory activity. Int. J. Nanomed. 2018, 13, 4133-4144. [CrossRef] [PubMed]

45. Bora, C.; Prabhu, R.; Patravale, V. Lymphatic Delivery: Concept, Challenges and Applications (INDIAN DRUGS Best Review Article Award 2017). Indian Drugs 2017, 54, 5-22.

46. Lombardo, D.; Kiselev, M.A.; Caccamo, M.T. Smart Nanoparticles for Drug Delivery Application: Development of Versatile Nanocarrier Platforms in Biotechnology and Nanomedicine. J. Nanomater. 2019, 2019, 26. [CrossRef]

47. Shabestari Khiabani, S.; Farshbaf, M.; Akbarzadeh, A.; Davaran, S. Magnetic nanoparticles: Preparation methods, applications in cancer diagnosis and cancer therapy. Artif. Cells Nanomed. Biotechnol. 2017, 45, 6-17. [CrossRef]

48. Elsheikh, M.A.; Elnaggar, Y.S.; Gohar, E.Y.; Abdallah, O.Y. Nanoemulsion liquid preconcentrates for raloxifene hydrochloride: Optimization and in vivo appraisal. Int. J. Nanomed. 2012, 7, 3787.

49. Tokuoka, T.; Tobe, H. Phylogenetic analyses of Malpighiales using plastid and nuclear DNA sequences, with particular reference to the embryology of Euphorbiaceae sens. str. J. Plant Res. 2006, 119, 599-616. [CrossRef] 
50. Vinogradova, T.I.; Aleksandrova, A.E.; Tschegoleva, R.A. Cephalosporins as possible methods of etiotropic therapy of tuberculosis. Probl. Tuberk. 1993, 45-48.

51. Jeevarathinam, A.S.; Lemaster, J.E.; Chen, F.; Zhao, E.; Jokerst, J. Photoacoustic Imaging Quantifies Drug Release from Nanocarriers via Redox Chemistry of Dye-Labeled Cargo. Angew. Chem. Int. Ed. 2019, 59, 4678-4683. [CrossRef] 